\title{
Land Use Proportion and Walking: Application of Isometric Substitution Analysis
}

\section{Authors}

Takemi Sugiyama (takemi.sugiyama@acu.edu.au) ${ }^{1,2}$

Jerome N. Rachele (j.rachele@unimelb.edu.au) ${ }^{3}$

Lucy D. Gunn (lucy.gunn@rmit.edu.au) ${ }^{4}$

Nicola W. Burton (n.burton@griffith.edu.au) ${ }^{5}$

Wendy J. Brown (wbrown@uq.edu.au) ${ }^{6}$

Gavin Turrell (gavin.turrell@deakin.edu.au) 3,4,7,8 $^{3}$

\section{Affiliations}

${ }^{1}$ Mary MacKillop Institute for Health Research, Australian Catholic University, Melbourne, Victoria, Australia

${ }^{2}$ Centre for Urban Transitions, Swinburne University of Technology, Melbourne, Victoria, Australia

${ }^{3}$ Centre for Health Equity, Melbourne School of Population and Global Health, University of Melbourne, Melbourne, Victoria, Australia

${ }^{4}$ Centre for Urban Research, RMIT University, Melbourne, Victoria, Australia

${ }^{5}$ School of Applied Psychology, Griffith University, Brisbane, Queensland, Australia

${ }^{6}$ Centre for Research on Exercise, Physical Activity and Health, University of Queensland, Brisbane, Queensland, Australia

${ }^{7}$ Centre for Population Health Research, Deakin University, Melbourne, Victoria, Australia

${ }^{8}$ School of Public Health and Social Work, Queensland University of Technology, Brisbane, Queensland, Australia

\section{Corresponding Author}

Takemi Sugiyama, PhD, MArch

Mary MacKillop Institute for Health Research, Australian Catholic University

215 Spring Street, Melbourne, Victoria, 3000, Australia

Tel: +61 (3) 92308262

Email: takemi.sugiyama@acu.edu.au 


\section{Acknowledgements}

The HABITAT study was supported by the Australian National Health and Medical Research

Council (NHMRC) Grants \#1047453, \#497236, and \#339718, with support from the Brisbane City

Council. JNR and LDG were supported by the NHMRC Centre for Research Excellence in

Healthy Liveable Communities Grant \#1061404. 


\begin{abstract}
Entropy measures of land use mix are a commonly used component of walkability. However, they present methodological challenges, and studies on their associations with walking have produced mixed findings. This study examined associations of the proportion of discrete land uses with walking, using isometric substitution models that take the complementary nature of land use proportions into account. Analysis of data collected from middle-aged adults living in Brisbane, Australia $(n=10794)$ found that replacing residential or other land with commercial land was associated with higher levels of walking. The isometric substitution approach may explain the potential impact of land use changes on residents' walking.
\end{abstract}

Keywords: Environment; Land use mix; Neighborhood; Physical activity 


\section{BACKGROUND}

2 Land use mix, or diverse land uses in a given geographical area, is a central principle of

3 contemporary urban planning practice: co-location of different types of land use is considered to

4 contribute to local economy, environment, and health (Hirt, 2016). Public health also recognizes

5 the importance of mixed land use, as research has found adverse health impacts of land use

6 separation policies and resultant sprawled, single-use, auto-dependent development (Ewing,

7 Schmid, Killingsworth, Zlot, \& Raudenbush, 2003). Having multiple land uses in a local area has

8 been regarded as an environmental initiative to enhance public health, because it may encourage

9 active modes of transport, typically walking (Frank et al., 2006). Commercial and recreational land

10 in proximity to residential areas provides residents with opportunities to walk to local services and

11 businesses and to walk for recreation. In an earlier study, which proposed the concept of the 3Ds

12 (density, design, and diversity) as key environmental factors that support walking, diversity was

13 mainly conceptualized as dissimilarity of land uses (Cervero, 1997).

15 Measuring land use mix, however, is a challenge. In academic research, land use mix is often operationalized as "entropy", which ranges from 0 to 1 , with 0 denoting a single land use within an area, and 1 indicating an equal distribution of different types of land use (Song, Merlin, \&

Rodriguez, 2013). This entropy measure of land use mix has been used as one of the components of the walkability index (Frank et al., 2010). However, studies using the entropy measure of land use mix as predictors of walking have produced inconsistent findings. A literature review has shown non-significant associations in two out of four studies examining relationships between the entropy measures of land use mix and walking for transport (Grasser, Van Dyck, Titze, \& mix and walking in about half the studies identified (Durand, Andalib, Dunton, Wolch, \& Pentz, 
2011). Researchers have also discussed methodological issues with the entropy measure and shown that the association between land use mix (or walkability with entropy using different combinations of land uses) and walking depends on which land uses are included in the calculation of entropy scores (Christian et al., 2011; Duncan et al., 2010). In addition, areas consisting of multiple land uses can have a high entropy score, even when they may not provide destinations for walking. For instance, the areas consisting of residential, industrial, and "other" land uses, where residents may have few daily destinations to walk, can have a similar entropy value to areas consisting of residential, commercial, and recreational land uses, which are likely to have more local destinations. Previous inconsistent findings may be due to land use mix measures focusing on the presence of different land use types rather than the presence of specific land use types.

In light of the inconsistent findings and methodological challenges in the entropy measure of land use mix, researchers have tried different methods to examine discrete land uses (Hirsch, Diez Roux, Rodriguez, Brines, \& Moore, 2013; McConville, Rodriguez, Clifton, Cho, \& Fleischhacker, 2011). For instance, proximity to specific destinations representing particular land use (e.g., grocery stores, parks) was found to be associated with more walking (Brown et al., 2009; McConville et al., 2011). The proportion of an area with a particular land use has also been associated with walking. A study on adults residing in six diverse localities in the U.S. found that two measures of walking for transport (any walking or $\geq 150 \mathrm{~min} /$ week of walking versus no walking) were consistently associated with the percentage of retail area, but not with the entropy score (Rodriguez, Evenson, Diez Roux, \& Brines, 2009). Another study that examined discrete land uses also reported that longer walking for errands was associated with a lower proportion of residential land and a higher proportion of recreational, commercial, and institutional land (Oliver, Schuurman, Hall, \& Hayes, 2011). 
50 Such proportional measures of land uses are promising because they are more straightforward to 51 understand and easier to communicate to practitioners and policy makers than entropy measures.

52 However, to have a realistic understanding of how land use proportions are related to walking, it is 53 important to consider the complementary nature of land use proportions, i.e., a higher proportion 54 of one land use means reduced proportions of other land use(s). Simply examining how an 55 increment in one land use is associated with a behavioral or health outcome (without considering 56 the displacement of another land use) may produce misleading findings. Recently, "isotemporal

substitution" has gained traction as a novel approach that addresses the potential impact of replacing one exposure element with another, where complementary relationships exist (Mekary, Willett, Hu, \& Ding, 2009). This approach has been used to examine to what extent replacing one type of accelerometer-measured physical activity (e.g., light-intensity activity) with another (e.g., moderate-to-vigorous activity) within the defined total time of activity could affect health-related outcomes (Buman et al., 2010; Yasunaga et al., 2017). Isotemporal substitution may be suitable for examining land use proportions, as the proportions complement each other within the defined total land area (i.e., the sum must add up to $100 \%$ ). The aim of this study is to examine how statistically replacing one land use with another (among residential, commercial, recreational, and other land uses) is associated with walking. We used "isometric substitution" rather than "isotemporal substitution" in this study as what is to be replaced is space but not time.

\section{METHODS}

\section{Study participants}

This cross-sectional study used baseline data from the HABITAT study. The Human Research Ethics Committee of the Queensland University of Technology (Ref. no. 3967H) gave ethics 
approval for the HABITAT study. Details about HABITAT's sampling design have been published elsewhere (Burton et al., 2009). Briefly, a multi-stage probability sampling design was used to select a stratified random sample $(n=200)$ of Census Collector's Districts (CCD - hereafter referred to as neighborhoods) from the Australian Bureau of Statistics (ABS), and from within each neighborhood, a random sample of people aged 40-65 years $(n=17,000)$. In 2007, of 16,127 who were eligible to participate, 11,035 returned the questionnaire with useable data (response rate: $69 \%)$.

\section{Outcomes}

Participants reported their frequency and duration of walking (to get to or from places, for recreation, and for exercise) in the last week. The duration of walking was categorized into one of three levels: (1) no walking; (2) walked > 0 and < $150 \mathrm{~min} /$ week (some walking); and (3) walked $\geq 150 \mathrm{~min} /$ week (sufficient walking). The frequency of walking was treated as a count variable. We used total walking (for transport and for recreation) in this study because existing research suggests linkages between commercial land use and walking for transport, and between recreational land use and walking for recreation (Sugiyama et al., 2012). However, it is unknown how switching land uses (e.g., replacing commercial area with recreational area, which may increase walking for transport but may decrease walking for recreation) influences overall walking. We seek to understand how the different scenarios of land use substitution may affect total walking.

\section{Exposures}

Land use data were obtained from the digital cadaster data of Brisbane City, where each land parcel was assigned a land use code according to its predominant use. For each participant's 
97 residential address, a 1-km street network buffer was drawn, and the proportion of each of the

98

following four land uses within the area were calculated: residential (land use for dwellings including caravan parks, retirement villages, residential care facilities); commercial/institutional (stores, restaurants/cafes, offices, hospitals, library, religious, educational, childcare); recreational (parkland, sports grounds, gardens, bushland); and other (factories, mining, warehouses, depots, construction sites, cemetery, agriculture/farm, forests, military). These four land uses were chosen based on the following considerations. Residential land is the dominant land use in urban areas, and this is where participants reside. Commercial/institutional land use provides residents with destinations to walk to, thus facilitating walking for transport, while recreational land use represents areas that are mainly used for recreational walking. Other land use may not offer walking destinations for most residents but is still needed to account for all the land area. The buffer size was chosen because a study on walking distance to various destinations found $1 \mathrm{~km}$ as approaching the maximum distance people walk (Millward, Spinney, \& Scott, 2013).

\section{Covariates}

Individual-level covariates included age, gender, education, occupation, household composition, household income, difficulty in doing physical activity, and the network distance to the nearest train station from each participant's home. We adjusted for the distance to train stations as these are not necessarily located in or near commercial areas in Brisbane. Study areas were ranked into quintiles according to the level of socio-economic disadvantage, Socio-Economic Indexes for Areas (Australian Bureau of Statistics, 2008), and this category was used as an area-level covariate.

\section{Statistical Analyses}


121 We conducted two types of regression models, single land use models and isometric substitution

122 models, to assess cross-sectional associations of land use with each walking measure, following 123 previous studies using the same approach on physical activities (Buman et al., 2010; Yasunaga et

124

125

126

127

128

129

130

131

132

133

134

135

al., 2017). The single land use model assessed each land use separately, without taking other land uses into account, adjusting for covariates. The single land use model in the case of residential land is expressed as follows:

$$
\text { Walking }=b_{1}(\text { residential area })+b_{5}(\text { total area })+b_{6}(\text { covariates }) \text {. }
$$

The coefficient $b_{1}$ can be interpreted as the effect of residential area holding total area constant. However, total area has no effect on the analyses, as this is a constant $(=100)$, when land uses are measured in percentage terms. This model does not specify which land use is replaced. The isometric substitution models examined the effect of an increment of a particular land use specifying another land use to be replaced. The model below shows a situation where residential land is substituted for another land use:

$$
\text { Walking }=b_{2}(\text { commercial area })+b_{3}(\text { recreational area })+b_{4}(\text { other area })+b_{5}(\text { total area })+b_{6}
$$
(covariates).

In this model, $b_{2}$ represents the effect of a unit amount substitution of commercial land with residential area, since the model adjusts for recreational, other, and total areas (they are held constant). An increment in commercial area automatically means the same amount reduction of residential area. Logistic regression analysis was used for the binary outcomes (some walking; sufficient walking). Negative binomial regression was applied for non-zero walking frequency due to the overdispersion of this variable. We excluded non-walkers in the frequency analysis because logistic regression models were used to assess differences between walkers and non-walkers. Considering that study areas had relatively small proportions of commercial, recreational, and other areas (mean: 6-7\%), we used 1\% as a unit amount for the analyses. Some participants did 
not have a particular land use within the $1 \mathrm{~km}$ buffer around their place of residence. In cases where land use could not be replaced, the data (those with less than $1 \%$ commercial area $=1,225$; less than $1 \%$ recreational area $=1,248$; and less than $1 \%$ other area $=1,014$ ) were excluded from the analyses in the corresponding isometric substitution models. All analyses adjusted for neighborhood level clustering. Stata 14 (StataCorp, College Station, TX) was used for analysis.

\section{Scenarios for isometric substitution analysis}

Isometric substitution models specify a target land use and a land use to be replaced by the target. For instance, a model can examine the potential impact of replacing commercial land use with residential land use. We examined the scenarios shown in Table 1. We considered all possible scenarios in this study for the sake of completeness. Some scenarios are more plausible in existing neighborhoods, i.e., Scenarios 3, 6, and 9 are equivalent to residential, commercial, and parkland development in green, brown, or gray field sites.

\section{RESULTS}

After excluding those with missing data for walking and key demographic variables $(n=241)$, data from 10,794 participants were retained for analyses. Table 2 shows the characteristics of the study sample. The study sample was broadly representative of the corresponding population (aged 4065) of Brisbane (Turrell et al., 2010). The mean size of the $1 \mathrm{~km}$ buffer area was 1.1 (SD: 0.4) $\mathrm{km}^{2}$. Participants lived in areas that were mostly residential (almost $80 \%$ on average), and about one fifth of them did not report any walking. The median walking frequency (excluding nonwalkers) was 4 times/week. The walking frequency was overdispersed: the mean was 5.0 (SD: 3.8) 
times/week, while its variance was 14.1. Correlation coefficients between land use proportions are shown in Table 3.

\section{(INSERT TABLE 2 AND 3 AROUND HERE)}

The results of single land use models, in which each land use was examined without specifying which land use was to be replaced, are shown in Table 4 . A 1\% increment in residential area was associated with $0.6 \%$ lower odds of some walking (versus no walking), while a $1 \%$ increment in commercial area was associated with about $2 \%$ higher odds of some and sufficient walking.

Recreational and other areas were not significantly associated with the walking outcomes in the single land use models. Walking frequency (excluding non-walkers) was not associated with any land use proportions.

The results of isometric substitution models are shown in Table 5. Replacing 1\% of commercial area with residential area (Scenario 1) was associated with about $2 \%$ lower odds of some and sufficient walking. Scenario 4 is the reverse situation of Scenario 1. The regression coefficients obtained in Scenario 4 were not completely "opposite" of those in Scenario 1, because those who lived in areas with $<1 \%$ commercial area were excluded in Scenario 1. Replacing recreational area with commercial area (Scenario 5) was associated with $2 \%$ higher odds of sufficient walking. Scenario 8 is the reverse situation of Scenario 5. Replacing other area with commercial area (Scenario 6) was associated with 1.5\% higher odds of some walking and $2 \%$ higher odds of sufficient walking. This is one of the plausible scenarios that produced significant findings. 
193

194 195 196 197 198 199

200 201 202 203 204 205 206 207

Scenario 11, the reverse situation of Scenario 6, showed an additional significant association for walking frequency: replacing $1 \%$ of commercial area with 'other' area was associated with $0.5 \%$ lower frequency of walking. No significant associations were observed for Scenario 2, 3, 7, 9, 10, and 12 .

\section{(INSERT TABLE 5 AROUND HERE)}

\section{DISCUSSION}

This study applied the isometric substitution approach to understand how substituting one land use with another is associated with walking measures, using data collected from mid-aged adults living in Brisbane, Australia. Overall, the findings illustrate the importance of commercial areas for walking. The single land use models found that an increment in commercial area was associated with more walking. In the isometric substitution model, replacing other area with commercial area, which is one of the plausible development scenarios, was also associated with more walking. The magnitude of the associations was similar to a less-likely scenario of substituting residential area with commercial area. The proportion of commercial area in the study areas was relatively low (mean: 8\%). Increasing this proportion, in place of residential or other areas, may encourage residents' walking. However, the study found few significant associations for (non-zero) walking frequency, suggesting that different land use scenarios may not affect how many times people (who reported walking) walk.

The study did not find a positive contribution of recreational land to the amount of walking. The single land use models showed non-significant associations of recreational area with the walking outcomes. Moreover, some isometric substitution models found that replacing commercial area 
with recreational area was associated with lower levels of walking (Scenario 8). Replacing other

area with recreational area (Scenario 9), which is a probable development pattern, also did not yield significant findings. It is possible that the size and quality of recreational area, typically parks, may be relevant. Research has shown that the presence of larger parks, which tend to have more amenities and facilities, is associated with more walking (Koohsari et al., 2018; Sugiyama, Francis, Middleton, Owen, \& Giles-Corti, 2010). In addition, an Australian study conducted in Sydney found that having a larger green space outside the local area (rather than within the local area) is associated with engagement in physical activity (Chong, Byun, Mazumdar, Bauman, \& Jalaludin, 2017). For many participants, Brisbane's large, well-maintained parklands with diverse amenities may be outside their local areas, and a number of smaller parks in the local areas may not contribute to their walking. Another issue is that the study did not measure the quality aspects of recreational land (e.g., facilities, maintenance), which are significantly associated with the use of and visits to such space (Cohen et al., 2015; Sugiyama et al., 2015). Some recreational land within the buffer area may not be suitable for walking (e.g., not accessible or poorly maintained). In the case where recreational land is well used by local residents, replacing recreational area with commercial area may not enhance residents' walking. For recreational land use, measuring only its total area may not be sufficient to understand its relationships with walking.

The study areas had a high proportion of residential area (almost $80 \%$ of the total land). Although the single land use models found that an increment in residential area was associated with lower odds of some walking, the findings of the isometric substitution models showed that more residential area was associated with less walking only when it was replaced with commercial area. It is difficult to decrease the proportion of residential land in existing neighborhoods, but new neighborhoods can have a lower proportion of residential area, potentially by increasing residential 
density. Having dense residential areas with a larger proportion of commercial land may promote residents' walking. For instance, let's suppose an area with $70 \%$ residential and $16 \%$ commercial land. This can be achieved by replacing $8 \%$ of residential land with the same amount of commercial land in the average area of this study ( $78 \%$ residential and $8 \%$ commercial). Such substitution would produce approximately $17 \%$ higher odds $(=2.1 \%$ higher odds [Scenario 4 ] per $1 \%$ replacement $\times 8 \%$ replacement) of meeting physical activity guidelines through walking alone.

\section{Limitations}

Several issues need to be considered in interpreting the findings of this study. First, the study measured land use types assigned, which may not truly reflect the way land parcels are actually used. In addition, land use intensity was not considered in the study. For instance, some commercial areas may include parcels where businesses are less relevant to typical residents, vacant, or closed. Further, the study cannot distinguish traditional local commercial areas with individual stores from "big-box" shopping centers. However, although people tend not to walk to these centers, the amount of walking within shopping centers may contribute significantly to weekly walking (Tudor-Locke, Burton, \& Brown, 2009). Vertical land use mix (e.g., commercial use on the ground floor and residential use on upper floors) was not considered in this study, as the digital cadaster data provided a "predominant" land use for each land parcel. Since land use can be allocated horizontally and vertically (particularly so in high density areas), it is of interest to take vertical land use mix into account and examine its impact. The study was conducted in Brisbane, where the study areas were mostly residential. The findings may not be applicable to denser areas with a higher proportion of commercial land or regional areas with larger proportions of industrial or agricultural land. The study used $1 \mathrm{~km}$ buffers to calculate the proportion of land uses. This distance is supported by an empirical study that investigated the distance adults would walk to 
various destinations (Millward et al., 2013), and a study that examined relationships between

266

walkability (including the entropy measure of land use mix) and walking found a limited impact of different buffer sizes on the associations (Villanueva et al., 2014). Nonetheless, $1 \mathrm{~km}$ (equivalent to a 20-minute walk distance) may be too far for some participants to walk. Further research with a smaller buffer size may be needed to confirm the findings of this study. The study did not consider the quality of streets to reach destinations. Residents living in areas with commercial land may not walk if streets in the area are not pedestrian friendly. Future studies may need to examine the joint impact of land use proportions and street characteristics on residents' walking. We used self-report walking measures, which can involve reporting errors and bias (Brown, Burton, Marshall, \& Miller, 2008). Land use proportions are compositional data, for which a new analytical approach is proposed in time-use epidemiology (Chastin et al., 2015; Pedišić, Dumuid, \& Olds, 2017). Future studies could benefit from employing compositional data analysis, which may further advance our understanding of how different proportions of land use are related to behavioral outcomes. Finally, this is a cross-sectional study. Although the study examined the potential "effect" of land use change scenarios, further longitudinal research would allow for stronger inferences of causality.

\section{Conclusion}

Addressing the challenges in measuring land use mix, this study focused on the proportion of discrete land uses and examined their associations with walking using the isometric substitution approach. The results of isometric substitution models suggest that replacing residential or other area with commercial area may increase the likelihood and amount of walking. The isometric substitution approach may be useful for understanding the potential impact of land use change scenarios in existing neighborhoods and may assist land use planning for new neighborhoods. 


\section{REFERENCES}

Australian Bureau of Statistics, 2008. Socio-Economic Indexes for Areas (SEIFA) - Technical Paper 2006. Canberra: Australian Bureau of Statistics.

Brown, B. B., Yamada, I., Smith, K. R., Zick, C. D., Kowaleski-Jones, L., Fan, J. X., 2009. Mixed land use and walkability: Variations in land use measures and relationships with BMI, overweight, and obesity. Health \& Place, 15(4), 1130-1141.

doi:10.1016/j.healthplace.2009.06.008

Brown, W. J., Burton, N. W., Marshall, A. L., Miller, Y. D., 2008. Reliability and validity of a modified self administered version of the Active Australia physical activity survey in a sample of mid-age women. Australian \& New Zealand Journal of Public Health, 32(6), 535-541. doi:10.1111/j.1753-6405.2008.00305.x

Buman, M. P., Hekler, E. B., Haskell, W. L., Pruitt, L., Conway, T. L., Cain, K. L., . . King, A. C., 2010. Objective light-intensity physical activity associations with rated health in older adults. American Journal of Epidemiology, 172(10), 1155-1165. doi:10.1093/aje/kwq249

Burton, N. W., Haynes, M., Wilson, L. A. M., Giles-Corti, B., Oldenburg, B. F., Brown, W. J., . . Turrell, G., 2009. HABITAT: A longitudinal multilevel study of physical activity change in mid-aged adults. BMC Public Health, 9. doi:10.1186/1471-2458-9-76

Cervero, R., Kockelman, K., 1997. Travel demand and the three D's: Density, diversity and design. Transportation Research Part D: Transport \& Environment, 2(3), 199-219. doi: 10.1016/S1361-9209(97)00009-6

Chastin, S. F. M., Palarea-Albaladejo, J., Dontje, M. L. \& Skelton, D. A. (2015). Combined effects of time spent in physical activity, sedentary behaviors and sleep on obesity and cardiometabolic health markers: A novel compositional data analysis approach. PLoS One, 10(10), e0139984. doi:10.1371/journal.pone.0139984 
Chong, S., Byun, R., Mazumdar, S., Bauman, A., Jalaludin, B. (2017). Effects of distant green space on physical activity in Sydney, Australia. Journal of Physical Activity \& Health, 14(1), 29-35. doi:10.1123/jpah.2016-0142

Christian, H. E., Bull, F. C., Middleton, N. J., Knuiman, M. W., Divitini, M. L., Hooper, P., . . Giles-Corti, B. 2011. How important is the land use mix measure in understanding walking behaviour? Results from the RESIDE study. International Journal of Behavioral Nutrition \& Physical Activity, 8, 55. doi:10.1186/1479-5868-8-55

Cohen, D. A., Han, B., Isacoff, J., Shulaker, B., Williamson, S., Marsh, T., . . Bhatia, R., 2015. Impact of park renovations on park use and park-based physical activity. Journal of Physical Activity \& Health, 12(2), 289-295. doi:10.1123/jpah.2013-0165

Duncan, M. J., Winkler, E., Sugiyama, T., Cerin, E., duToit, L., Leslie, E., Owen, N., 2010. Relationships of land use mix with walking for transport: Do land uses and geographical scale matter? Journal of Urban Health, 87(5), 782-795. doi:10.1007/s11524-010-9488-7

Durand, C. P., Andalib, M., Dunton, G. F., Wolch, J., Pentz, M. A., 2011. A systematic review of built environment factors related to physical activity and obesity risk: Implications for smart growth urban planning. Obesity Reviews, 12(5), e173-182. doi:10.1111/j.1467789X.2010.00826.X

Ewing, R., Schmid, T., Killingsworth, R., Zlot, A., Raudenbush, S., 2003. Relationship between urban sprawl and physical activity, obesity, and morbidity. American Journal of Health Promotion, 18(1), 47-57. doi:10.4278/0890-1171-18.1.47

Frank, L. D., Sallis, J. F., Conway, T. L., Chapman, J. E., Saelens, B. E., Bachman, W., 2006. Many pathways from land use to health: Associations between neighborhood walkability and active transportation, body mass index, and air quality. Journal of the American Planning Association, 72(1), 75-87. doi: 10.1080/01944360608976725 
Frank, L. D., Sallis, J. F., Saelens, B. E., Leary, L., Cain, K., Conway, T. L., Hess, P. M., 2010. The development of a walkability index: Application to the Neighborhood Quality of Life Study. British Journal of Sports Medicine, 44(13), 924-933.

doi:10.1136/bjsm.2009.058701

Grasser, G., Van Dyck, D., Titze, S., Stronegger, W., 2013. Objectively measured walkability and active transport and weight-related outcomes in adults: A systematic review. International Journal of Public Health, 58(4), 615-625. doi:10.1007/s00038-012-0435-0

Hirsch, J. A., Diez Roux, A. V., Rodriguez, D. A., Brines, S. J., Moore, K. A., 2013. Discrete land uses and transportation walking in two US cities: The Multi-Ethnic Study of Atherosclerosis. Health \& Place, 24, 196-202. doi:10.1016/j.healthplace.2013.09.007

Hirt, S. A., 2016. Rooting out mixed use: Revisiting the original rationales. Land Use Policy, 50, 134-147. doi:10.1016/j.landusepol.2015.09.009

Koohsari, M. J., Badland, H., Mavoa, S., Villanueva, K., Francis, J., Hooper, P., . . Giles-Corti, B., 2018. Are public open space attributes associated with walking and depression? Cities, 74, 119-125. doi:10.1016/j.cities.2017.11.011

McConville, M. E., Rodriguez, D. A., Clifton, K., Cho, G., Fleischhacker, S., 2011. Disaggregate land uses and walking. American Journal of Preventive Medicine, 40(1), 25-32. doi:10.1016/j.amepre.2010.09.023

Mekary, R. A., Willett, W. C., Hu, F. B., Ding, E. L., 2009. Isotemporal substitution paradigm for physical activity epidemiology and weight change. American Journal of Epidemiology, 170(4), 519-527. doi:10.1093/aje/kwp163

Millward, H., Spinney, J., Scott, D., 2013. Active-transport walking behavior: Destinations, durations, distances. Journal of Transport Geography, 28, 101-110. doi:10.1016/j.jtrangeo.2012.11.012 
Oliver, L., Schuurman, N., Hall, A., Hayes, M., 2011. Assessing the influence of the built environment on physical activity for utility and recreation in suburban metro Vancouver. BMC Public Health, 11. doi:10.1186/1471-2458-11-959

Pedišić, Ž., Dumuid, D. \& Olds, T. S., 2017. Integrating sleep, sedentary behaviour, and physical activity research in the emerging field of time-use epidemiology: Definitions, concepts, statistical methods, theoretical framework, and future directions. Kinesiology, 49, 252-269.

Rodriguez, D. A., Evenson, K. R., Diez Roux, A. V., Brines, S. J., 2009. Land use, residential density, and walking: The Multi-Ethnic Study of Atherosclerosis. American Journal of Preventive Medicine, 37(5), 397-404. doi:10.1016/j.amepre.2009.07.008

Song, Y., Merlin, L., Rodriguez, D., 2013. Comparing measures of urban land use mix. Computers Environment \& Urban Systems, 42, 1-13. doi:10.1016/j.compenvurbsys.2013.08.001

Sugiyama, T., Francis, J., Middleton, N. J., Owen, N., Giles-Corti, B., 2010. Associations between recreational walking and attractiveness, size, and proximity of neighborhood open spaces. American Journal of Public Health, 100(9), 1752-1757. doi:10.2105/ajph.2009.182006

Sugiyama, T., Gunn, L. D., Christian, H., Francis, J., Foster, S., Hooper, P., . . Giles-Corti, B., 2015. Quality of public open spaces and recreational walking. American Journal of Public Health, 105(12), 2490-2495. doi:10.2105/ajph.2015.302890

Sugiyama, T., Neuhaus, M., Cole, R., Giles-Corti, B., Owen, N., 2012. Destination and route attributes associated with adults' walking: A review. Medicine \& Science in Sports \& Exercise, 44, 1275-1286. doi:10.1249/MSS.0b013e318247d286

Tudor-Locke, C., Burton, N. W., Brown, W. J., 2009. Leisure-time physical activity and occupational sitting: Associations with steps/day and BMI in 54-59 year old Australian women. Preventive Medicine, 48(1), 64-68. doi:10.1016/j.ypmed.2008.10.016

Turrell, G., Haynes, M., Burton, N. W., Giles-Corti, B., Oldenburg, B., Wilson, L., Giskes, K., 
Brown, W. J., 2010. Neighbourhood disadvantage and physical activity: Baseline results from the HABITAT multilevel longitudinal study. Annals of Epidemiology, 20(3), 171181. doi:10.1016/j.annepidem.2009.11.004

Villanueva, K., Knuiman, M., Nathan, A., Giles-Corti, B., Christian, H., Foster, S., Bull, F., 2014. The impact of neighborhood walkability on walking: Does it differ across adult life stage and does neighborhood buffer size matter? Health \& Place, 25, 43-46.

doi:10.1016/j.healthplace.2013.10.005

Yasunaga, A., Shibata, A., Ishii, K., Koohsari, M. J., Inoue, S., Sugiyama, T., . . Oka, K., 2017. Associations of sedentary behavior and physical activity with older adults' physical function: An isotemporal substitution approach. BMC Geriatrics, 17(1), 280. doi:10.1186/s12877-017-0675-1 


\section{TABLES}

Table 1. Scenarios examined for isometric analysis

\begin{tabular}{clll}
\hline Scenario & More land for & Displaced land use & Land uses held constant \\
\hline 1 & Residential & Commercial & Recreational, Other \\
2 & Residential & Recreational & Commercial, Other \\
$3 \ddagger$ & Residential & Other & Commercial, Recreational \\
4 & Commercial & Residential & Recreational, Other \\
5 & Commercial & Recreational & Residential, Other \\
$6 \ddagger$ & Commercial & Other & Residential, Recreational \\
7 & Recreational & Residential & Commercial, Other \\
8 & Recreational & Commercial & Residential, Other \\
$9 \ddagger$ & Recreational & Other & Residential, Commercial \\
10 & Other & Residential & Commercial, Recreational \\
11 & Other & Commercial & Residential, Recreational \\
12 & Other & Recreational & Residential, Commercial \\
\hline
\end{tabular}

† more plausible land use change scenario 
Table 2. Characteristics of study participants in $2007(\mathrm{~N}=10,794)$

\begin{tabular}{|c|c|c|}
\hline & & Mean (SD) or $\%$ \\
\hline Age & & $51.2(7.1)$ \\
\hline Gender & Women & 56.0 \\
\hline \multirow[t]{4}{*}{ Education } & High school only & 39.3 \\
\hline & Trade/business certificate & 17.7 \\
\hline & Diploma & 11.5 \\
\hline & University degree & 31.5 \\
\hline \multirow[t]{5}{*}{ Occupation } & Manager/professionals & 33.6 \\
\hline & White collar & 22.1 \\
\hline & Blue collar & 14.2 \\
\hline & Not working & 14.1 \\
\hline & Unclassified $^{\mathrm{b}}$ & 15.9 \\
\hline \multirow[t]{5}{*}{ Household composition } & Single with no child & 21.0 \\
\hline & Single with child/ren & 8.7 \\
\hline & Couple with no child & 26.5 \\
\hline & Couple with child/ren & 42.7 \\
\hline & Other & 1.1 \\
\hline \multirow[t]{6}{*}{ Household income $^{\text {a }}$} & Less than $\$ 26,000$ & 9.4 \\
\hline & $\$ 26,000-\$ 51,999$ & 18.2 \\
\hline & $\$ 52,000-\$ 72,799$ & 14.7 \\
\hline & $\$ 72,800-\$ 129,999$ & 25.9 \\
\hline & $\$ 130,000$ or more & 17.3 \\
\hline & Unclassified $^{\mathrm{b}}$ & 14.5 \\
\hline \multirow{3}{*}{$\begin{array}{l}\text { Difficulty to do physical } \\
\text { activity }^{c}\end{array}$} & Yes & 12.2 \\
\hline & No & 86.1 \\
\hline & Missing & 1.7 \\
\hline \multirow[t]{4}{*}{ Proportion of land use, $\%$} & Residential & $78.1(11.6)$ \\
\hline & Commercial/institutional & $7.6(5.8)$ \\
\hline & Recreational & $6.9(6.3)$ \\
\hline & Other & $7.4(8.1)$ \\
\hline \multicolumn{2}{|l|}{ Distance to train station, $\mathrm{km}$} & $3.4(2.4)$ \\
\hline \multirow[t]{3}{*}{ Walking category ${ }^{\mathrm{d}}$} & No walking & 20.2 \\
\hline & Some walking & 44.5 \\
\hline & Sufficient walking & 35.3 \\
\hline $\begin{array}{l}\text { Non-zero walking frequency, } \\
\text { times/wk }\end{array}$ & Median [25th-75th percentile] & $4[2-6]$ \\
\hline
\end{tabular}

\footnotetext{
${ }^{a}$ Gross annual household income in Australian dollars

b Includes missing values, "others" (occupation), "do not know/do not want to answer" (income)

"Yes: those who agreed or strongly agreed to "disability makes it difficult to do physical activity"

d Some walking: Walked $>0$ and $<150 \mathrm{~min} / \mathrm{wk}$; Sufficient walking: Walked $\geq 150 \mathrm{~min} / \mathrm{wk}$
} 
Table 3. Pearson's correlation coefficients between land use proportions

\begin{tabular}{lcccc}
\hline & Residential & Commercial & Recreational & Other \\
\hline Residential & - & & & \\
Commercial & -0.51 & - & & \\
Recreational & -0.57 & 0.12 & - & \\
Other & -0.62 & -0.09 & -0.06 & - \\
\hline
\end{tabular}

$\mathrm{p}<0.001$ for all the coefficients 
Table 4. Single land use models examining the association of residential, commercial (including institutional), recreational, and other land with each walking outcome

\begin{tabular}{|c|c|c|c|}
\hline Land use & $\begin{array}{l}\text { Some walking } \\
\text { versus no walking } \\
(\mathrm{N}=6,981) \\
\text { OR }(95 \% \mathrm{CI})\end{array}$ & $\begin{array}{c}\text { Sufficient walking } \\
\text { versus no walking } \\
(\mathrm{N}=5,992) \\
\text { OR }(95 \% \mathrm{CI})\end{array}$ & $\begin{array}{c}\text { Non-zero walking } \\
\text { frequency } \\
(\mathrm{N}=8,247) \\
\mathrm{RR}(95 \% \mathrm{CI})\end{array}$ \\
\hline Residential & $0.994(0.989,0.999)^{*}$ & $0.994(0.988,1.000) \dagger$ & $1.001(1.000,1.003)$ \\
\hline Commercial & $1.018(1.006,1.029)^{* *}$ & $1.021(1.008,1.033)^{* * *}$ & $1.000(0.997,1.003)$ \\
\hline Recreational & $1.005(0.995,1.016)$ & $1.001(0.990,1.012)$ & $0.999(0.996,1.002)$ \\
\hline Other & $1.001(0.993,1.008)$ & $1.001(0.993,1.009)$ & $0.998(0.996,1.001)$ \\
\hline
\end{tabular}

$\dagger \mathrm{p}<.1, * \mathrm{p}<.05, * * \mathrm{p}<.01, * * * \mathrm{p}<.001$

Regression coefficients (OR: odds ratios, RR: relative rate) correspond to a $1 \%$ increment in land use proportion.

All models adjusted for age, gender, education, occupation, household composition, income, difficulty to do physical activity, distance to train station, area-level of socio-economic disadvantage, and corrected for clustering at neighborhoods. 
Table 5. Isometric substitution models examining the effects of replacing one land use with another on each walking outcome

\begin{tabular}{|c|c|c|c|c|c|}
\hline Scenario & $\begin{array}{l}\text { Target land use } \\
\text { (1\% higher) }\end{array}$ & $\begin{array}{l}\text { Displaced } \\
\text { land use } \\
\text { (1\% lower) }\end{array}$ & $\begin{array}{l}\text { Some walking } \\
\text { versus no walking } \\
\text { OR }(95 \% \mathrm{CI})\end{array}$ & $\begin{array}{l}\text { Sufficient walking versus } \\
\text { no walking } \\
\text { OR }(95 \% \mathrm{CI})\end{array}$ & $\begin{array}{l}\text { Non-zero walking } \\
\text { frequency } \\
\text { RR }(95 \% \mathrm{CI})\end{array}$ \\
\hline 1 & & Commercial & $0.982(0.970,0.995)^{* *}$ & $0.977(0.964,0.990) * * *$ & $0.998(0.995,1.001)$ \\
\hline 2 & Residential & Recreational & $0.995(0.984,1.006)$ & $0.998(0.986,1.010)$ & $1.000(0.998,1.003)$ \\
\hline $3+$ & & Other & $0.998(0.991,1.006)$ & $0.997(0.989,1.005)$ & $1.002(0.999,1.004)$ \\
\hline 4 & & Residential & $1.018(1.006,1.029)^{* *}$ & $1.021(1.009,1.033)^{* * *}$ & $1.000(0.998,1.003)$ \\
\hline 5 & Commercial & Recreational & $1.011(0.994,1.028)$ & $1.019(1.001,1.037)^{*}$ & $1.002(0.997,1.006)$ \\
\hline $6 t$ & & Other & $1.015(1.002,1.029)^{*}$ & $1.020(1.006,1.034)^{* *}$ & $1.003(0.999,1.007)$ \\
\hline 7 & & Residential & $1.004(0.994,1.014)$ & $0.999(0.988,1.010)$ & $0.999(0.996,1.003)$ \\
\hline 8 & Recreational & Commercial & $0.985(0.968,1.003) \dagger$ & $0.976(0.958,0.994)^{*}$ & $0.997(0.993,1.002)$ \\
\hline $9 \ddagger$ & & Other & $1.004(0.992,1.017)$ & $0.999(0.985,1.013)$ & $1.001(0.997,1.005)$ \\
\hline 10 & & Residential & $1.002(0.995,1.009)$ & $1.002(0.995,1.011)$ & $0.998(0.996,1.001)$ \\
\hline 11 & Other & Commercial & $0.980(0.966,0.995)^{* *}$ & $0.975(0.960,0.991)^{* *}$ & $0.995(0.992,0.999)^{*}$ \\
\hline 12 & & Recreational & $0.996(0.983,1.009)$ & $0.999(0.985,1.014)$ & $0.998(0.995,1.001)$ \\
\hline
\end{tabular}

$\dagger \mathrm{p}<.1, * \mathrm{p}<.05, * * \mathrm{p}<.01, * * * \mathrm{p}<.001$

+ more plausible land use change scenario

Regression coefficients (OR: odds ratios, RR: relative rate) correspond to a $1 \%$ increment in target land use proportion.

All models adjusted for age, gender, education, occupation, household composition, income, difficulty to do physical activity, distance to train station, area-level socio-economic disadvantage, and corrected for clustering at neighborhoods. 